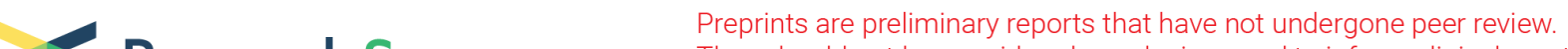 $\begin{array}{ll}\text { Research Square } & \text { They should not be considered conclusive, used to inform clinical practice, } \\ \text { or referenced by the media as validated information. }\end{array}$
}

\section{Influence of Water Supply Conditions and Water Storage Containers on Aedes Mosquito Abundance in Makassar City, Indonesia}

\section{Ruslan La Ane}

Ehime University Faculty of Engineering Graduate School of Science and Engineering: Ehime Daigaku Kogakubu Daigakuin Rikogaku Kenkyuka

\section{Von Ralph Dane M. Herbuela}

Ehime University Faculty of Engineering Graduate School of Science and Engineering: Ehime Daigaku

Kogakubu Daigakuin Rikogaku Kenkyuka

Isra Wahid

Universitas Hasanuddin Fakultas Kedokteran

\section{Andi Susilawaty}

Universitas Islam Negeri Alauddin Makassar

Hasanuddin Ishak

Universitas Hasanuddin Fakultas Kesehatan Masyarakat

\section{Erniwati Ibrahim}

Universitas Hasanuddin Fakultas Kesehatan Masyarakat

\section{Ming-Chih Chiu}

Ehime University Faculty of Engineering Graduate School of Science and Engineering: Ehime Daigaku Kogakubu Daigakuin Rikogaku Kenkyuka

Kozo Watanabe ( $\square$ watanabe_kozo@cee.ehime-u.ac.jp )

Ehime University

\section{Research}

Keywords: Water supply, intentional and unintentional water storage containers, vector abundance, piecewise-SEM

Posted Date: February 15th, 2021

DOI: https://doi.org/10.21203/rs.3.rs-189214/v1

License: (c) (i) This work is licensed under a Creative Commons Attribution 4.0 International License. Read Full License 


\section{Abstract}

Background: High water demand accompanied with an unreliable piped water supply has forced urban residents to store water in containers. This situation potentially increases the number of breeding sites for mosquito vectors, such as Aedes.

Method: This study aimed to test the hypothesis if piped water connection availability, tap water use, and highly stable tap water supply can help minimize the use of water storage containers as well as the presence of larvae and number of adult Aedes mosquitoes. We conducted a community-based entomological survey of 343 households from 36 neighborhoods or Rukun Tetangga in Makassar City, Indonesia. Our model based on the hypothesis was tested by piecewise structural equation modeling analysis.

Results: A significant negative correlation was found between the stability of tap water supply and the number of water storage containers $(-0.16, P<0.05)$. Of the two categories of water storage containers, the unintentional water storage containers demonstrated a significantly $(P<0.001)$ higher effect on larval prevalence than the intentional one. Further, both container categories have significant indirect effects on the number of adult mosquitoes mediated by larval presence.

Conclusion: Improving water supply condition, particularly by assuring a stable tap water supply, could minimize the use of intentional water storage containers. Furthermore, a regular community-wide health education program that targets the elimination of unintentional water storage containers, which can be breeding grounds for Aedes larvae mosquitoes, is necessary.

\section{Background}

The presence of water in both natural and artificial containers is important in a mosquito's life cycle. The two most common species Aedes aegypti and Aedes albopictus are competent vectors of dengue, yellow fever, and chikungunya viruses [1]. These species live in close contact with humans [2] and exploit artificial and natural containers inside and near households for their immature life stages: these containers include water storage containers, discarded rainwater-retaining materials, tree holes, and plant axils [3].

In most studies examining the relationship between household water containers and the risk of mosquitoborne diseases, water containers were not classified according to their function (i.e., intentional and unintentional water storage containers) [4-8]. These studies emphasized that households use various water containers mainly to reserve water because of the uncertainty in tap water availability. DharChowdhury et al. [9] introduced the following five categories of water containers according to their functions: 1) household chores, 2) ornamental purposes, 3) amenities, 4) discarded containers, and 5) repairing and reconstruction purposes. However, having five categories seems unnecessary when specifically examining the relationship between the availability of water storage containers and the household's water supply condition. The household chore category is the only category that is mostly 
related to water storage practice, while the rest of the categories can be merged into one, which is the unintentional water storage category. Thus, the present study classified the water storage containers into two: intentional and unintentional water storage containers. Intentional water storage containers are utilized for storing water for daily household use, whereas the unintentional water storage containers are not intended for storing water. Using these two categories facilitates in the formulation of a more targeted control strategy that is specific to the type of water storage containers at the household level.

Water storage containers in households have been extensively reported to play a vital role in the presence and increase of immature vector (larvae and pupae) prevalence. Stewart Ibarra et al. (2013) demonstrated that households that stored water containers such as cisterns or tanks had greater odds of containing $A$. aegypti pupae than those households that either did or did not store water but did not have a cistern or tank [10]. The same results were reported by Barera et al. (1993) in Venezuela [5]. From their surveillance, $71 \%(245 / 344)$ of the households had at least one container with $A$. aegypti immatures, and nearly half (788/2036) of the water containers were infested with the Aedes aegypti immatures. Moreover, Nguyen et al. [4] conducted a study in rural areas of southern Vietnam and found that as the number of water storage containers increases, the number of $A$. aegypti larvae also increases. Interestingly, these entomological studies only investigated the prevalence of larvae, not adult mosquitoes, in water storage containers. We considered such exclusion as a limitation because compared with immature mosquitoes, adult female Aedes mosquitoes transmit the virus to humans [11]. However, to our knowledge, no studies had investigated the relationship between the water storage containers and the abundance of adult Aedes mosquitoes.

The abundance of mosquito vectors in water storage containers are measured by various indices, with house index $(\mathrm{HI})$ and container index $(\mathrm{Cl})$ as the most widely used; meanwhile adult mosquito index ( $\mathrm{Al})$, as the name implies, is the index used for adult mosquito abundance. $\mathrm{HI}$ refers to the proportion of households with larvae, $\mathrm{Cl}$ is the proportion of water-holding containers with larvae, and $\mathrm{Al}$ is the proportion of adult mosquitoes in households. The Al is ideal use because it is highly accurate in predicting the occurrence of dengue transmission risk [12].

The prevalence of immature vectors (e.g., pupae) is also reportedly linked to water supply conditions such as the absence of piped water connection and unstable supply of tap water in households. A multicountry study, which included Myanmar, India, Indonesia, Philippines, Sri Lanka, and Thailand, investigated the association between water supply and Aedes pupal production; in Myanmar, irregular supply of tap water as well as the absence of piped water had the highest pupae per hectare index (PHI) among all those of countries involved [7]. Another multicountry study including Latin America, particularly in Ecuador, found a similar condition; this study revealed that not all households within the study cluster sites had access to piped water connection and that water supply was irregular and unavailable through the public network on a daily basis. Thus, households tend to acquire water from wells or rivers and store it in water storage containers [8]. In dry and wet seasons, 443 and 582 water storage containers contribute to the $\mathrm{PHI}$ of 35.0 and 150.2 , respectively [8]. However, with regard to larval prevalence and 
adult mosquito abundance, their relationship with water supply conditions remains insufficiently investigated.

Makassar City is one of the largest and most urbanized cities in the eastern part of Indonesia. Covering an area of approximately $175.77 \mathrm{~km}^{2}$, this city is inhabited by roughly 1.5 million people, with $1.29 \%$ annual population growth in 2018 [13]. In the same year, the Regional Water Supply Company or the Perusahaan Daerah Air Minum (PDAM) of Makassar was only able to serve approximately $62.01 \%$ of the total population [14]. This water company operates five water treatment plants (WTP) that have a total design capacity of 2375 liters per second (L/s). However, the actual production is only $2354 \mathrm{~L} / \mathrm{s}$ because of losses in the distribution system (e.g., leaks in old pipes) and seasonality of raw water quantities [15]. Furthermore, dengue epidemiology in Makassar increases. In 2015, 142 dengue cases were reported, with an incidence rate (IR) of 10.08 per 100,000 population and a case fatality rate (CFR) of $3.52 \%$ [16]. Unfortunately, these rates increased almost twice (248 cases) in 2016 (IR, 27.35 per 100,000 population; CFR, 0.5\%) [17].

In this study, the prevalence of water storage containers was estimated in each household, categorizing them into two: 1) intentional water storage containers and 2) unintentional water storage containers. Then, we compared the prevalence of Aedes larvae between these two categories to identify the preferred breeding site of mosquitoes. We also examined the relationship of water storage container categories with water supply conditions (i.e., the availability of tap water connection, main source of clean household water, and the level of tap water supply stability) and with larval prevalence and adult Aedes mosquito abundance. We also assessed the relationship between larval prevalence and the indices $\mathrm{HI}, \mathrm{Cl}$, and Al. On the basis of the literature, first, we hypothesized that water storage containers would be prevalent in the households, which would also have a high prevalence of larval mosquitoes. Second, we hypothesized that the availability of piped water connection, use of tap water, and a highly stable supply of tap water in a household would contribute to the reduction in the number of water storage containers, eventually decreasing larval prevalence and adult Aedes mosquito abundance. This study further determined the relationship between the three indices and found a positive correlation among them.

\section{Methods}

\subsection{Study and sampling design}

A household-based cross-sectional entomological survey was conducted from January 1 to February 27, 2018 in Makassar City, the capital of South Sulawesi, Indonesia. This city is located at 119 $24^{\prime}-17^{\prime} 38^{\prime \prime}$ east longitude and 5 $5^{\circ}-6^{\prime} 1^{\prime \prime}$ south latitude (Fig. 1). Makassar has 14 subdistricts (Kecamatan) that are divided into 144 villages (Kelurahan). These villages were further divided into 4982 neighborhoods (Rukun Tetangga) or (RT). Each Kelurahan has an average of 34 RTs. The number of households per RT was identified using a two-stage cluster sampling method. First, a sample size of 377 households was recommended to assume that $50 \%$ of the households had larvae or adult Aedes mosquitoes, with a $5 \%$ margin of error and $95 \%$ confidence level ( $a=0.05$; critical value/Z-score of 1.96) based on a household 
population size of 20,000 (no information on the exact total number of households in all of the RTs). Second, we divided the 34 RTs by the recommended household sample size $(n=377)$ to identify the recommended number of households per RT $(n=11)$. However, we recruited households less than the recommended number (range: $4-10$ ) in 35 out of 36 RTs (97\%). Of which, two RTs had only five participating households; thus, we had to add two RTs, bringing a total of 36 RTs.

All of the selected RTs met the following inclusion criteria: a. received water services from PDAM (or Regional Water Supply Company); b. 80-90\% of the households belonged to low-to-middle family (average of 4 members) monthly income brackets (8-40 USD) based on the average income of 3893 USD gross domestic product per capita in $2018[18,19]$. Using the random selection algorithm of Excel, we randomly selected the households from the list provided by the leader (Ketua) of each RT. In cases when a list was unavailable in an RT, we coded each household with a unique identifier (e.g., 001 to 050) and picked numbers that corresponded to each household. Although all the included RTs received water services from one source, not all households tended to have piped connection. Others resorted to groundwater sources because of limited water supply. In fact, only $62 \%$ of the households per RT (average of 50 households) can be supplied with highly stable water services [14].

We directly observed 343 households (average of 10 households per RT) from 36 RTs by inspecting their water storage containers and their larva and adult mosquito collection. The household's water supply condition, piped water connection availability, types of main water source, and tap water supply stability were also evaluated. All necessary information on each investigated container, including the types of containers based on their function (intentional and unintentional water storage containers), volume, and the number of containers, were documented on an observation log sheet form.

\subsection{Water storage containers and larva and adult Aedesmosquito collections}

All water containers in the target households were inspected and classified into two main categories based on their functions: 1) intentional water storage containers (e.g., tank, bucket, washbasin, drum, jar, and jerrican) and 2) unintentional water storage containers (e.g., water dispenser tray, fridge water tray, flower pot, pet drinking bowl, old and used home appliances, discarded materials such as used tire, and natural water storage site such as tree-trunk hole) (Fig. 2). Larvae were also collected from these water storage containers through a larval collection method. This method was based on the operational guide for assessing the productivity of $A$. aegypti breeding sites issued by the World Health Organization (WHO), with some modified procedures [20]. All containers that were sampled for larval collection were open and had no covers; those that were closed, with seals, or consistently covered were excluded. For small containers containing $<1 \mathrm{~L}$ of water, all larvae were collected using a pipette in which the container was either emptied or filtered using a sieve. If the containers had more than $1 \mathrm{~L}$ of water (e.g., buckets, wash basins, earthen jar, jerricans, car tires, water dispenser trays, or small fixed containers where emptying was not practical) with good visibility/low larval density ( $<50$ individuals), a water dipper and a 
sieve were used. While the use of nets best collected larvae from high-volume water containers, based on our collection, cement tanks and plastic and metal drums ( $500 \mathrm{~L}$ water capacity) only had a maximum of $100 \mathrm{~L}$ of water; thus, we still used dipper and sieve, considering that most of them only had approximately 50-80 individuals. All collected larvae were stored in vials, which were transported to the laboratory for identification based on the pictorial keys of Rueda [21].

For adult mosquito collection, we installed two commercially available UV-light mosquito traps (Krisbow ${ }^{\circledR}$ GM-909) in each household for 48 hours. The traps were placed inside the households, mostly in the family room or bedroom. All collected adult mosquitoes were transferred to a plastic container and transported to the laboratory for morphological identification according to the taxonomic key for Aedes species (aegypti and albopictus) to separate them from other species (e.g., Culex) [21]. The actual number of the adult mosquitoes collected per household was used to identify abundance.

\subsection{Water Supply Conditions}

Water supply conditions included the availability of piped water connection, water source, and tap water supply stability. Regarding piped water connection, we determined whether the households had available piped water connection or not; those with piped water connection were scored " 1 ", otherwise " 0 ". Water source referred to the main source of water in the households (i.e., tap water and ground water); those with tap water source were scored " 1 ", and those with groundwater supply source were scored "2". Tap water supply stability data was the average self-reported length of tap water supply (in hours) that can be accessed in a day. A 24-hour access to water supply per day indicated high stability; meanwhile, low water stability and medium water stability clusters were based on the total maximum hours ( 23 hours), with the computed interval size of 11.5 hours each. Thus, low water stability was defined as $<11.6$ hours of water supply access per day, and medium stability referred to 11.6-23 hours per day. High, medium, and low stability of water supply were scored " 3 ", "2", and " 1 ", respectively. The households without piped water connection were considered as having a highly stable water supply because they had an alternative source of water (i.e., groundwater) in all of the included RTs.

\subsection{Statistical Data Analysis}

The frequency of water storage containers in each household was pooled into two categories (intentional and unintentional) to identify its prevalence from the total number of water storage containers because of the following reasons: each household had different types of water storage containers, some types of water containers were only present in some of the households (e.g., jerrican and earthen jar), and other households only had intentional water storage containers while others do not. Thus, pooling the frequencies according to the water storage container categories to identify its prevalence was more appropriate than comparing them per household. Each container was scored " 1 " if it had larvae; 
otherwise, it was scored " 0 ". Moreover, to identify which category had the higher number of larvae, we pooled the number of containers with larvae per water storage container category. The difference between the frequencies of intentional and unintentional water storage containers with and without larvae was determined by chi-square test. Unlike parametric tests, chi-square test is not sensitive to unequal sample sizes between two independent variables, such as our data (787 intentional water storage containers vs. 80 unintentional water storing containers). We also computed the odds-ratio effect sizes to measure the proportion differences between the two container classifications with and without larvae.

This study is exploratory in terms of testing the hypothesis (model) that water supply conditions (i.e., piped water connection availability, water source, and tap water supply stability) influence the number of intentional and unintentional water storage containers, which determine larval prevalence and adult mosquito abundance in the household level. Thus, we used piecewise structural equation modeling (piecewise-SEM), which is appropriate for not normally distributed data and useful in testing and quantifying direct and indirect effects between predictor and response variables that were recognized using a single model $[22,23]$. The goodness-of-fit of the model was assessed using Shipley's test of direct separation (d-sep test). Furthermore, Fisher's $\mathrm{C}$ statistic was associated with all the unspecified paths from the hypothesized network of relationships (e.g., the linkage between water source and tap water supply stability in our case). If one or more of these unspecified paths had significance in the presentation of the observed data (a chi-square test is run on the Fisher's $C$ statistic and the chi-square's $P$ value is $<0.05$ ), the model was not a good fit [24]. In other words, these missing paths contained necessary information; hence, the data were not represented well by the model.

The number of water storage containers with larvae was transformed into the following: HI wherein the number of households with Aedes larvae was divided by the number of inspected households and then multiplied by 100 , and $\mathrm{Cl}$ wherein the number of water storage containers with Aedes larvae was divided by the total number of inspected water storage containers and then multiplied by 100 . Meanwhile, the number of adult mosquitoes was transformed into Al wherein the number of adult mosquitoes was divided by the number of inspected households and then multiplied by 100 . The numbers of inspected vectors and households used for computing all the indices were in the RT level. To calculate the correlation values between these indices, Spearman's rank correlation (rs) (two-tailed) including ShapiroWilk and Kolmogorov-Smirnov normality tests revealed that the index data were not normally distributed [25]. All of the statistical tests were conducted using the built-in packages in $\mathrm{R}$ program version 3.5.2 [26], R package "epiR" (version 1.0-11) for the chi-square test [27], and R package "piecewise-SEM" (version 2.0.2) for the SEM analysis [23].

\section{Results}

\subsection{Water storage containers and larval prevalence}


From the 343 households included in this study, 867 water storage containers were identified in which $787(91 \%)$ were intentional water storage containers and $80(9 \%)$ were unintentional water storage containers. Furthermore, 16\% (125/787) and 79\% (63/80) of the intentional and unintentional water storage containers had larvae (Fig. 3).

Chi-square analyses showed that the unintentional water storage containers had a significantly higher larval prevalence $(P<0.001)$ than the intentional ones $\left(X^{2}=169.53 ; \mathrm{df}=1\right)$. Odds-ratio computation also indicated that the unintentional water storage containers were 3.7 times more likely to have larvae than the intentional ones. Supplementary Table S1 presents additional information on the prevalence of larvae in each storage container category.

\subsection{Water supply conditions, water storage containers, and vector prevalence and abundance}

The path diagram (Fig. 4) shows the piecewise-SEM analysis results. Overall, the model was found to be acceptable according to the $d$-sep test because none of the unspecified paths was significant at the 0.05 level (Fisher's $\mathrm{C}=5.53 \mathrm{df}=4, P=0.237$ ). Moreover, the tap water stability had a significant negative correlation with the number of intentional water storage containers (with coefficient estimation of -0.16 , $P<0.05)$. Furthermore, the number of intentional and unintentional water storage containers demonstrated positive significant effects on larval presence, with a coefficient estimation of $0.22(P<$ $0.01)$ and $3.16(P<0.001)$, respectively. In addition, the larval presence $(0.27, P<0.01)$ had a positive significant effect on the number of adult mosquitoes. Supplementary Table S2 lists further information on the proportion of the households' water supply conditions by the number of water storage container categories.

A Spearman rank with continuity correction of the relationship among the larval indices $(\mathrm{HI}$ and $\mathrm{Cl})$ and adult mosquito index (Al) revealed that there were significant correlations $(p<0.05)$ between $\mathrm{HI}$ and $\mathrm{Cl}\left(r_{\mathrm{s}}\right.$ $=0.46 ; P=0.004)$ and $\mathrm{HI}$ and $\mathrm{Al}\left(r_{\mathrm{s}}=0.35 ; P=0.037\right)$.

\section{Discussion}

The main findings partially support our hypothesis that a stable tap water supply could minimize the use of water storage containers. This finding was true among intentional water storage containers but not among the unintentional ones. The significant negative relationship between tap water supply stability and the number of intentional water storage containers at households indicated that low stability (i.e., < 12 hours available) of tap water had an effect on the increasing number of such containers. The mean number of water storage containers for households with low stability of tap water supply was $2.73( \pm 2.5$ SD) compared with those with high stability of tap water supply (i.e., 2.16; \pm 1.9 SD) per household (Supplementary Table S3). 
In Barranquilla City, Colombia, residents still opted to store water in elevated tanks, ground tanks, or drums despite a relatively stable supply of tap water [28]. During the surveillance, we observed that most households in our study site in Makassar tended to store their clean water in containers because their water supply was inadequately available or interrupted unpredictably. The Japan International Cooperation Agency (JICA) reported that in 2012, the water supply in Makassar lost by $30 \%$ because of leaks in old pipe lines [15]. In 2018, water supply loss had increased to $46.7 \%$, which aggravated the lack of a stable water supply [14]. Although significant, this finding should be interpreted cautiously because of the weak relationship between the tap water supply stability and the number of intentional water storage containers, as revealed by a relatively low coefficient $(-0.16)$. Overall, although the model obtained a low $R^{2}$ value of 0.03 , we must take note how the changes in the values of tap water stability were associated with the changes in the values of intentional water storage containers.

Interestingly, the piecewise-SEM analysis also showed that piped water connection and water source had no significant effect on the number of intentional and unintentional water storage containers, possibly because of the availability of a stable tap water supply. Most of the households with piped water connection had a more stable water supply, which decreases the use of intentional and unintentional water storage containers, than those without piped water connection. Meanwhile, households with less stable tap water supply tended to collect water from wells, thereby increasing the use of intentional and unintentional water storage containers.

Furthermore, the numbers of intentional water storage containers $(P<0.01)$ and unintentional water storage containers $(P<0.001)$ has a positive significant effect on larval presence. This finding partially supports our hypothesis. However, the unintentional water storage containers had significantly $(P<0.001)$ higher effect on larval presence than the intentional ones. Moreover, chi-square analysis showed similar results that unintentional water storage containers $(79 \%)$ contain significantly $(P<0.001)$ more larvae than the intentional ones $(16 \%)$. The relatively low larval prevalence in intentional water storage containers might be explained by the fact that the water in these containers was used by the residents on a daily basis. The daily use of water, which is used primarily in drinking and cooking, washing of clothes, bathing, house cleaning, and worshipping needs [29], shortened the water retention time in the containers. In 2007, the Ministry of Public Works and Public Housing in Indonesia reported that the average household water use in urban areas is $144 \mathrm{~L}$ per person a day. During our surveillance, an average of 4 to 5 members share in using water from the containers with a capacity of 3-500 liters. Hence, the water stored in the containers was replaced daily, causing a relatively high disturbance of the complete (approximately 10 days) aquatic development cycle (from an egg to an adult) of Aedes mosquitoes [30]. Vessel emptying within 7 days has a strong correlation with the decreasing pupal production [31].

The significantly higher prevalence of unintentional water storage containers with larvae implies that these kinds of containers are ideal breeding sites of vector mosquitoes, especially Aedes species. Recent studies support this result that unintentional water storage containers (e.g., refrigerator trays, flower pots, and plant axils) are suitable oviposition sites for Aedes mosquitoes [32, 33]. Most households in our study site in Makassar often had flower pots that were not drained regularly and water dispenser trays 
that were often left empty and remained stagnant for a relatively long period of time. Similarly, a study conducted by Dhar-Chowdhury et al. (2016) found that Aedes larvae had a statistically significant increase in households where water was stored for more than 3 days [9]. Thus, the longer the water is kept in the containers, the higher the possibility for Aedes mosquitoes to proliferate.

Moreover, both container categories had indirect effects on the number of adult mosquitoes through the presence of larvae (Fig. 4). This finding is indicated by the total effect of the intentional water storage containers $(0.22 \times 0.27=0.06)$ and the unintentional water storage containers $(3.16 \times 0.27=0.85)$ on the number of adult mosquitoes mediated by larval presence. Both values were larger than those of the direct effect of the corresponding variables (indicated by coefficient estimation of 0.01 and 0.12 , respectively) on the number of adult mosquitoes (Fig. 4). Therefore, the households with a high prevalence of larval infestations in water storage containers might also have produced a high number of adult mosquitoes. This finding is similar to that of previous studies in which the prevalence and distribution of water storage containers at the households have been linked to adult mosquito abundance [34, 35]. Spearman correlation analyses also showed the same trend wherein the number of containers with larvae or $\mathrm{Cl}$ has a significant positive correlation $(P=.004)$ with the households with larvae or HI. Further, the mediating effect of the larval presence on adult mosquito abundance can also be supported by the significant positive correlation $(P=.037)$ between $\mathrm{HI}$ and $\mathrm{Al}$.

According to the estimated index for Aedes larvae in each RT based on household data ( $\mathrm{HI})$, nearly $90 \%$ of all the RTs had a medium risk for dengue transmission. This result correlates to the report that the dengue risk in Makassar is at its peak during the rainy months of January and February [36]. Although this study was conducted during the said months, using $\mathrm{HI}$ alone does not necessarily predict the risk for dengue transmission because this index has no correlation with the increased risk for dengue infection $[37,38]$. Thus, using $\mathrm{HI}$ as the sole indicator of dengue risk transmission is considered as a limitation. Further, compared with the index for immature mosquitoes, Al demonstrates high accuracy in predicting dengue transmission or dengue prevalence (receiver operating characteristic's area under the curve of 83.8\%) [12]. Although we have Al data, we lack information on the number of dengue cases in each Kelurahan to investigate the relationship between the two. Thus, rather than using $\mathrm{HI}$ alone, we recommend future studies to include dengue case and investigate whether it significantly correlates with Al to produce a more reliable outcome for dengue transmission risk analysis $[12,39,40,41]$.

One of the major limitations in our study is our inability to differentiate A. aegypti from A. albopictus larvae. Although focusing on $A$. aegypti larvae is ideal because of its high vectorial capacity for dengue, separating the two Aedes larvae species was difficult when we placed them in one small vial $(2.5 \mathrm{ml})$, especially in cases where $>10$ larvae were observed from each container category. Future studies should consider not placing more than 10 larvae in a vial for easier morphological identification. Another limitation is the low number of households per RT. Although it was the recommended sample size based on our multistage sampling method, including more households per RT or area (e.g. village or neighborhoods) would allow each RT to be well represented. Another limitation is the list we used for 
selecting households. We had extremely limited information on how the lists were compiled, limiting our ability to produce random spatial samples.

\section{Conclusions}

This study highlights that a stable tap water supply could minimize the use of intentional water storage containers. Importantly, the unintentional water storage containers have a robust contribution to the prevalence of Aedes larvae. Hence, a regular community-wide health education and breeding site eradication program that targets these unintentional water storage containers, which tend to be neglected by household members, must be implemented.

\section{Abbreviations}

RT

Rukun Tetangga

SEM

Structural equation modeling

PDAM

Perusahaan Daerah Air Minum (or Regional Water Supply Company)

WTP

Water treatment plant

$\mathrm{L} / \mathrm{s}$

Liter per second

IR

Incidence rate

CFR

Case fatality rate

WHO

World Health Organization

OR

Odds ratio

SD

Standard deviation

JICA

Japan International Cooperation Agency

PUSKESMAS

Pusat Kesehatan Masyarakat (or Community Health Center)

\section{Declarations}




\section{Ethics approval and consent to participate}

This study was approved by the Makassar City Office and the local administrative area such as subdistrict (Kecamatan) and village (Kelurahan) offices and has been approved for exemption from review by the Health Research Ethics Committee of Hasanuddin University (ethics approval number: UH18080487) because the study involved no greater than minimal risk among the participants. Verbal informed consent (sufficient for exempt research) from the heads of the households (18 years old and above) was obtained after we read and explained a verbal version of a consent form (contains the study's purpose, procedures, risks, benefits, etc.). They were informed that their participation in the study was voluntary and they may stop their participation any time. Forms and questionnaires were coded for their protection and privacy.

\section{Consent for publication}

Not applicable.

\section{Availability of data and materials}

The data analyses results supporting the conclusions are included within the article and its summaries are presented in additional files.

\section{Competing interests}

The authors declare that they have no competing interests.

\section{Funding}

This study was supported by the Japan Society for the Promotion of Science (JSPS) Grant-in-Aid for Scientific Research (19KK0107, 19H01144), JSPS and DG-RSTHE Bilateral Joint Research Projects (JPJSBP120198107), JSPS Core-to-Core Program B. Asia-Africa Science Platforms, and Endowed Chair Program of the Sumitomo Electric Industries Group Corporate Social Responsibility Foundation, which had no role in the design, data collection, statistical analysis and writing of this manuscript.

\section{Author contributions}

Author R.L.A. designed the study, collected the data, conducted the interviews, analysed the data and written this manuscript. Authors I.W, H.I., \& E.I. assisted in the research permit approval and supervised the data collection. Author A.S. worked with R.L.A. for coordinating data collection and provided 
comments on the initial drafts of this manuscript. Author M.-C.C. worked with R.L.A. on the data analysis, interpreted the results, and reviewed the manuscript. Author V.R.D.M.H. worked with R.L.A. on manuscript writing, review and editing as well as provided guidance on manuscript submission to the journal. Author K.W. supervised the data gathering and provided guidance and comments on the analysis and the initial drafts of this manuscript. All authors have contributed to and have approved the final manuscript.

\section{Acknowledgements}

The authors would like to thank Muhammad Wardiman, Ririn Suwahyuni, Muhammad Rafi, Jumriani, and Armiati for their assistance in the data collection procedure. We would also like to thank the office of the Mayor of Makassar City, all the Heads of the Kecamatan and Kelurahan for their approval and support in the conduct of this study. Most importantly, we are grateful to all the households who participated in this study.

\section{References}

1. Morrison AC, Zielinski-Gutierrez E, Scott TW, Rosenberg R. Defining challenges and proposing solutions for control of the virus vector Aedes aegypti. PLoS Med. 2008; 5(3): e68. doi:10.1371/ journal.pmed.0050068.

2. Kraemer MU, Sinka ME, Duda KA, Mylne AQ, Shearer FM, Barker CM, et al. The global distribution of the arbovirus vectors Aedes aegypti and Ae. albopictus. Elife. 2015;4: e08347. https://doi.org/10.7554/ eLife.08347 PMID: 26126267.

3. Ferdousi F, Yoshimatsu S, Ma E, Sohel N, Wagatsuma Y. Identification of Essential Containers for Aedes Larval Breeding to Control Dengue in Dhaka, Bangladesh. Trop Med Health. 2015; 43: 253264. https://doi.org/10.2149/tmh.2015-16 PMID: 26865829.

4. Nguyen L.A.P. et al. Abundance and prevalence of Aedes aegyptiimmatures and relationships with household water storage in rural areas in southern Vietnam, International Health. Volume 3, Issue 2, June 2011, Pages 115-125, https://doi.org/10.1016/j.inhe.2010.11.002.

5. Barrera R, Avila TJ, Gonzalez-Tellez S. Unreliable supply of potable water and elevated aedes aegypti larval indices: A causal relationship? J Am Mosq Control Assoc. 1993; 9: 189-195. PMID: 8350076.

6. Thamappalo S., Chongsuwiwatwong V., Geater A., Lim A., and Choomalee K. Socio-demographic and environmental factors associated with aedes breeding places in phuket, Thailand. SOUTHEAST ASIAN J TROP MED PUBLIC HEALTH. 2005; Vol 36 No. 2.

7. Arunachalam N, Tana S, Espino FE, Kittayapong P, Abeyewickreme W, Wai KT, Tyagi BK, Kroeger A, Sommerfeld J, Petzold M: Eco-Bio-Social determinants of dengue vector breeding: a multi country study in urban and peri-urban Asia. Bull World Health Organ 2010, 88:173-184.

8. Quintero J, Brochero H, Manrique-Saide P, Barrera-Pérez M, Basso C, Romero S, et al. Ecological, biological and social dimensions of dengue vector breeding in five urban settings of Latin America: a multi-country study. BMC Infect Dis. 2014;14(1):1. 
9. Dhar-Chowdhury, P., Haque, C. E., Lindsay, R., \& Hossain, S. Socioeconomic and Ecological Factors Influencing Aedes aegypti Prevalence, Abundance, and Distribution in Dhaka, Bangladesh. The American journal of tropical medicine and hygiene. 2016; 94(6), 1223-1233. doi:10.4269/ajtmh.150639.

10. Stewart Ibarra AM, Ryan SJ, Beltra'n E, Mejı'a R, Silva M, et al. Dengue Vector Dynamics (Aedes aegypti) Influenced by Climate and Social Factors in Ecuador: Implications for Targeted Control. PLoS ONE. 2013; 8(11): e78263. doi:10.1371/journal.pone.0078263.

11. Wijayanti SPM, Sunaryo S, Suprihatin S, McFarlane M, Rainey SM, Dietrich I, et al. Dengue in Java, Indonesia: Relevance of Mosquito Indices as Risk Predictors. PLoS Negl Trop Dis. 2016; 10(3): e0004500. doi:10.1371/journal.pntd.0004500.

12. Chang F-S, Tseng Y-T, Hsu P-S, Chen C-D, Lian I-B, Chao D-Y. Re-assess Vector Indices Threshold as an Early Warning Tool for Predicting Dengue Epidemic in a Dengue Non-endemic Country. PLoS Negl Trop Dis. 2015; 9(9): e0004043. doi:10.1371/ pntd.0004043.

13. Statistics of Makassar. Makassar municipality in figures 2019.

14. Kinerja BUMD Penyelenggara SPAM Wilayah III [Internet]. 2019. Available from: http://sim.ciptakarya.pu.go.id/bppspam/detail_profile/55.

15. Tjandraatmadja G, Ahmad A, Selintung M, Kirono D, Larson S, Salman D, et al. Context and challenges in urban water and wastewater services for Makassar, South Sulawesi, Indonesia. A report prepared for the CSIRO-AusAID Research alliance, CSIRO. 2012.

16. Health Office of Makassar. Municipality of Makassar Health Profile 2015.

17. Ministry of Health, Republic of Indonesia, Dengue national report by provinces. Sub-Directorate of Arbovirus, Directorate General for Infectious Diseases, Ministry of Health, Republic of Indonesia 2016.

18. Razafimandimby, A. R. 2017. Middle-Class Composition and Growth in Middle-Income Countries. ADBI Working Paper 753. Tokyo: Asian Development Bank Institute. Available: https://www.adb.org/publications/middle-class-composition-and-growth-middle-incomecountries.

19. The World Bank, 2019. GDP (current US\$) Indonesia. Available: https://data.worldbank.org/indicator/NY.GDP.MKTP.CD? end=2019\&locations=ID\&start=1990\&view=chart.

20. Operational Guide for Assessing the Productivity of Aedes aegypti Breeding Sites. Geneva, Switzerland: World Health Organization and Special Programme for Research and Training in Tropical Diseases; 2011.ISBN: 978-92-4-150268-9 available: https://www.who.int/tdr/publications/tdr-research-publications/sop-pupal-surveys/en/

21. Rueda LM. 2004. Pictorial keys for the identification of mosquitoes (Diptera: Culicidae) associated with Dengue virus transmission. Zootaxa 589: 1 - 60.

22. Grace, J.B. (2006) Strucutral Equation Modeling and Natural Systems. Cambridge University Press, New York, NY. 
23. Lefcheck JS. piecewiseSEM: Piecewise structural equation modeling in R for ecology, evolution, and systematics. Methods in Ecology and Evolution. 2016; 7(5), 573-579. doi: 1111/2041210X.12512, http://dx.doi.org/10.1111/2041-210X.12512.

24. Shipley B. Confirmatory path analysis in a generalized multilevel context. Ecology. 2009.

25. Dhimal, M.; Aryal, K.K.; Dhimal, M.L.; Gautam, I.; Singh, S.P.; Bhusal, C.L; Kuch, U. Knowledge, attitude and practice regarding dengue fever among the healthy population of highland and lowland communities in central Nepal. PLoS ONE 2014, 9, e102028.

26. R Core Team. R: A language and environment for statistical computing. $R$ foundation for statistical computing. Vienna, Austria. 2018; URL https://www.R-project.org/.

27. Mark Stevenson with contributions from Telmo Nunes, Cord Heuer, Jonathon Marshall, Javier Sanchez, Ron Thornton, Jeno Reiczigel, Jim Robison-Cox, Paola Sebastiani, Peter Solymos, Kazuki Yoshida, Geoff Jones, Sarah Pirikahu, Simon Firestone, Ryan Kyle, Johann Popp, Mathew Jay and Charles 2020; epiR: Tools for the Analysis of Epidemiological Data. R package version 1.0-11. https://CRAN.R-project.org/package=epiR.

28. Romero-Vivas, C.M.E, Arango-Padillla, P., and Falconar, A.K.I. Pupal-productivity surveys to identify the key container habitats of Aedes aegypti (L.) in Barranquilla, the principal seaport of Colombia. Annals of Tropical Medicine \& Parasitology. 2006; Vol. 100, supplement No. 1, S87-S95.

29. Ministry of Public Works and Public Housing, Republic of Indonesia. Pemakaian Air Rumah Tangga Perkotaan 144 Liter per hari [news]. 2007; Retrieved from https://www.pu.go.id/berita/view/4175/pemakaian-air-rumah-tangga-perkotaan-144-liter-perhari

30. Centers for Disease Control and Prevention. Mosquito Life Cycle [Fact sheet]. 2019; Retrieved from https://www.cdc.gov/dengue/communication-resources/factsheets-posters.html

31. Padmanabha H, Soto E, Mosquera M, Lord CC, Lounibos LP. Ecological links between water storage behaviors and Aedes aegypti production: implications for dengue vector control in variable climates. Ecohealth. 2010; 7: 78-90. Available: http://www.ncbi.nlm.nih.gov/pubmed/20358255. Accessed 28 March 2019. doi: 10.1007/s10393-010-0301-6 PMID: 20358255.

32. Paul KK, Dhar-Chowdhury P, Emdad Haque C, Al-Amin HM, Goswami DR, Heel Kafi MA, et al. Risk factors for the presence of dengue vector mosquitoes, and determinants of their prevalence and larval site selection in Dhaka, Bangladesh. PLoS One. 2018;13(6):1-19.

33. Wilke ABB, Vasquez C, Mauriello PJ, Beier JC. Ornamental bromeliads of Miami-Dade County, Florida are important breeding sites for Aedes aegypti (Diptera: Culicidae). Parasites and Vectors. 2018;11(1).

34. Agha SB, Tchouassi DP, Bastos ADS, Sang R. Assessment of risk of dengue and yellow fever virus transmission in three major Kenyan cities based on Stegomyia PLoS Negl Trop Dis. 2017; 11(8): e0005858. https://doi.org/10.1371/journal.pntd.0005858.

35. Khin Thet Wai, Natarajan Arunachalam, Susilowati Tana, Fe Espino, Pattamaporn Kittayapong, W Abeyewickreme, Dilini Hapangama, Brij Kishore Tyagi, Pe Than Htun, Surachart Koyadun, Axel Kroeger, Johannes Sommerfeld \& Max Petzold. Estimating dengue vector 
abundance in the wet and dry season: implications for targeted vector control in urban and periurban Asia, Pathogens and Global Health. 2012; 106:8, 436-445, DOI:

10.1179/2047773212Y.0000000063.

36. Health Office of Makassar. Municipality of Makassar Health Profile 2017.

37. Honório NA, Nogueira RMR, Codeço CT, Carvalho MS, Cruz OG, Magalhães MDAFM, et al. Spatial evaluation and modeling of dengue seroprevalence and vector density in Rio de Janeiro, Brazil. PLoS Negl Trop Dis. 2009;3(11):1-11.

38. Arboleda S, Jaramillo-O N, Peterson AT. Spatial and temporal dynamics of Aedes aegypti larval sites in Bello, Colombia. J Vector Ecol. 2012;37(1):37-48.

39. Bowman LR, Runge-Ranzinger S, McCall PJ. Assessing the Relationship between Vector Indices and Dengue Transmission: A Systematic Review of the Evidence. PLoS Negl Trop Dis. 2014; 8(5): e2848. doi:10.1371/journal.pntd.0002848.

40. Rubio-Palis Y, Perez-Ybarra LM, Infante-Ruiz M, Comach G, UrdanetaMarquez L. Influence of climatic variables on dengue cases and abundance of Aedes aegypti (Diptera: Culicidae) in Maracay, Venezuela. Boletin De Malariologia Y Salud Ambiental. 2011; 51: 145-157.

41. Correa PR, Franca E, Bogutchi TF. Aedes aegypti infestation and occurrence of dengue in the city of Belo Horizonte, Brazil. Rev Saude Publica. 2005; 39: 33-40. Available: http://www.ncbi.nlm.nih.gov/pubmed/15654458.

\section{Figures}




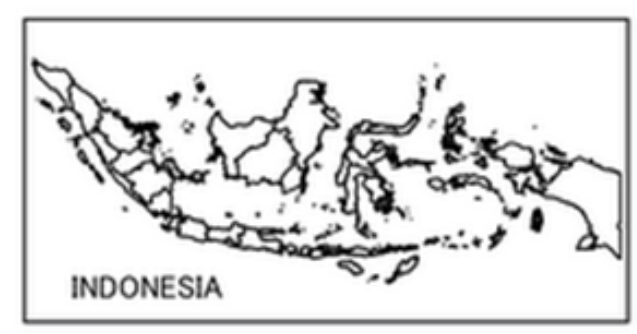

\section{Map of Makassar City}

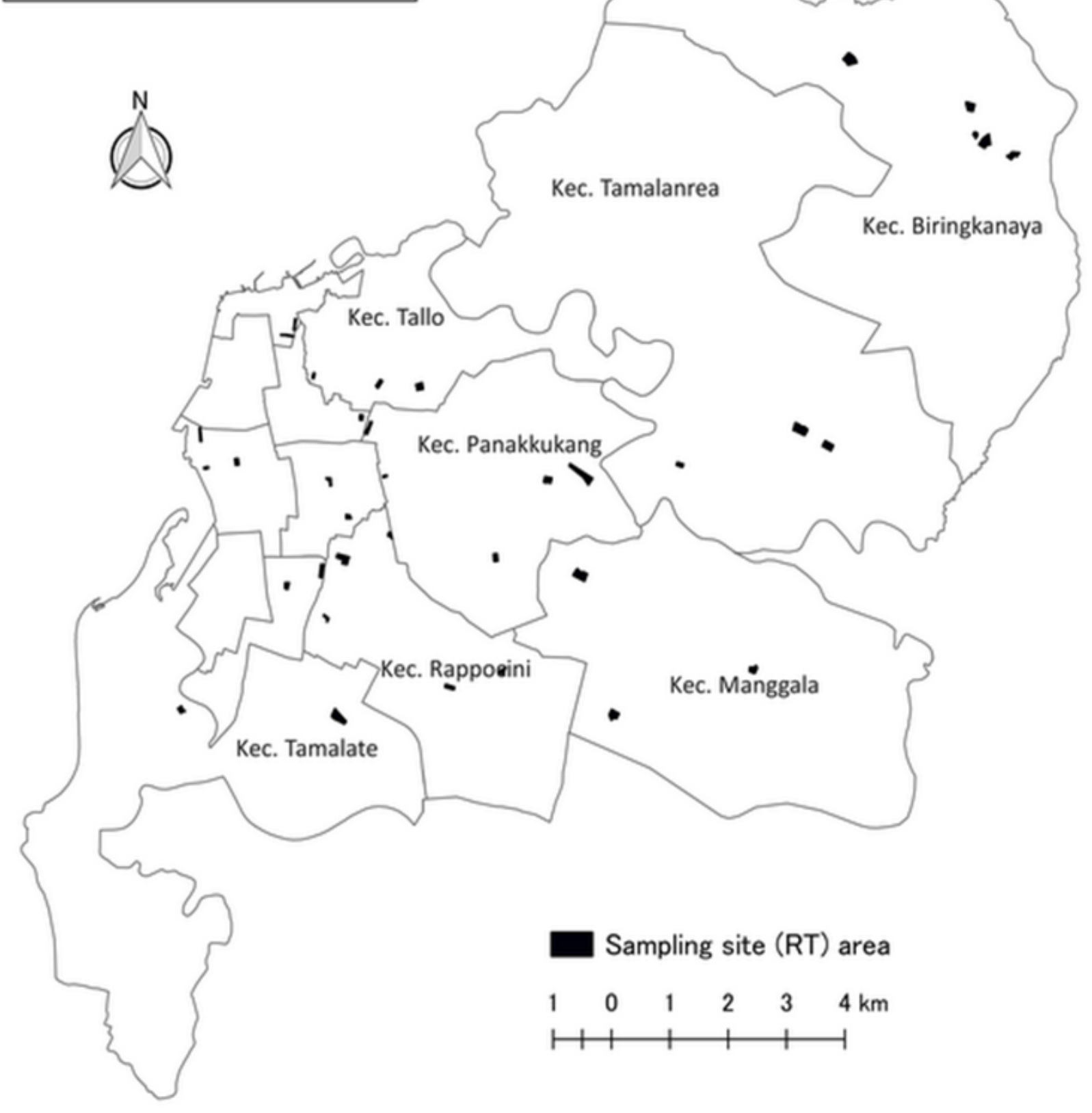

\section{Figure 1}

Map of Makassar City, Indonesia. Note: The designations employed and the presentation of the material on this map do not imply the expression of any opinion whatsoever on the part of Research Square concerning the legal status of any country, territory, city or area or of its authorities, or concerning the delimitation of its frontiers or boundaries. This map has been provided by the authors. 

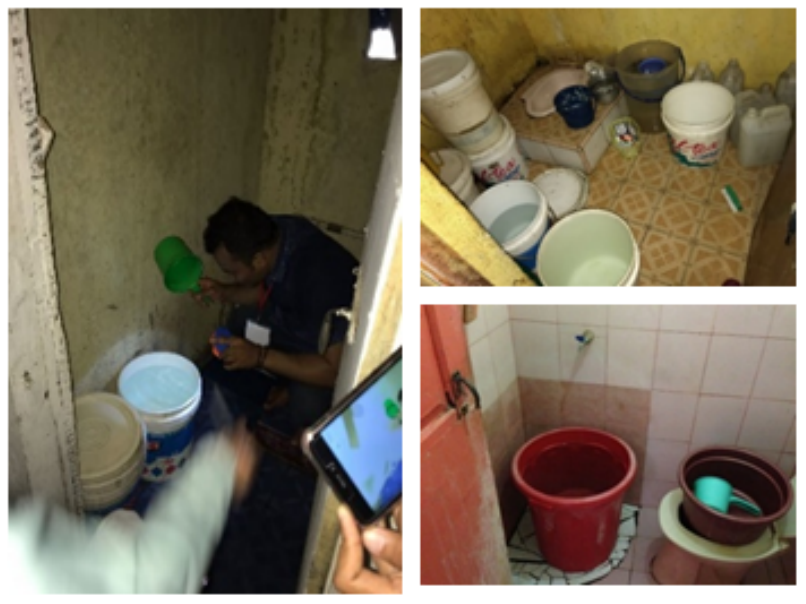

(a)
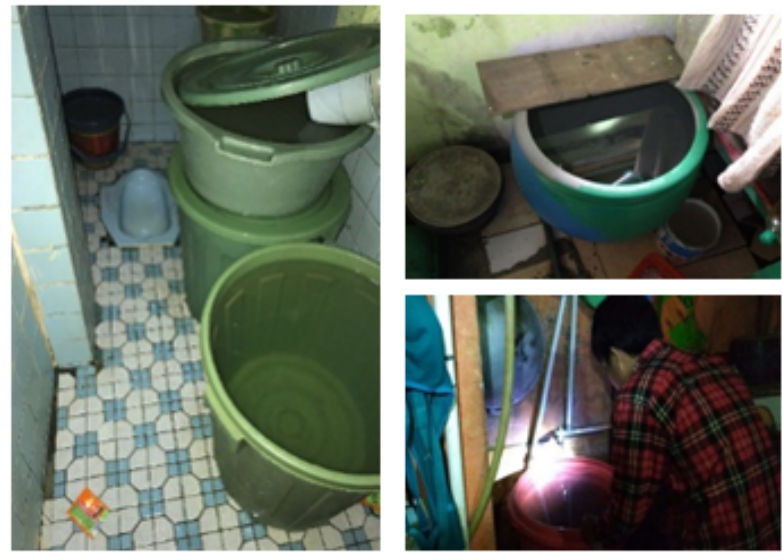

(b)
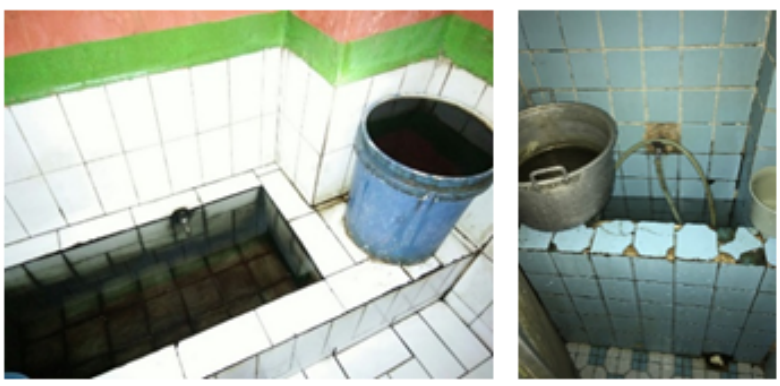

(c)
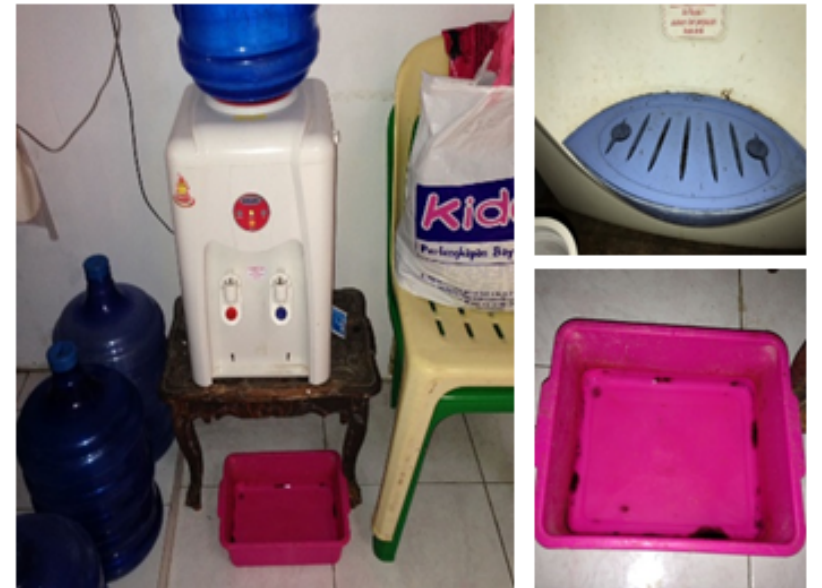

(d)

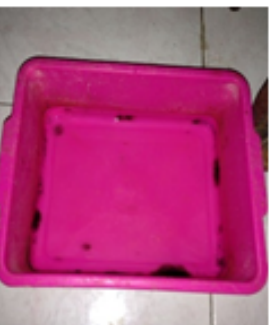

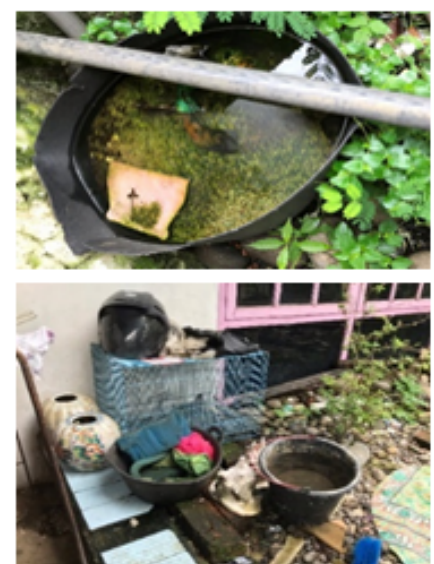

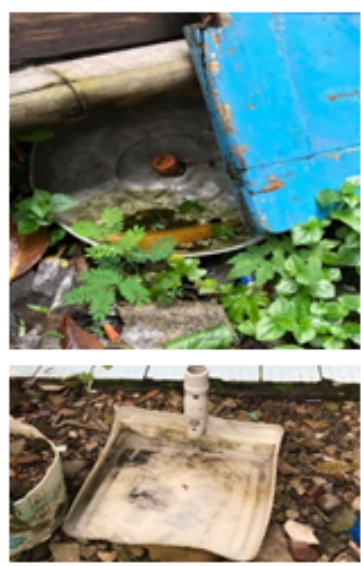

(e)
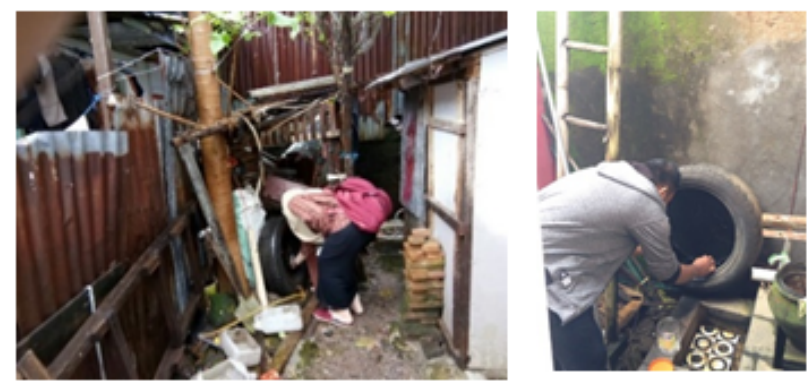

(f)

\section{Figure 2}

Typical water storage containers in the households. Intentional water containers: a)bucket, b) plastic drums, c) cement tanks; Unintentional water storage containers: d) water dispenser trays, e) discarded materials, f) tires. 


\section{Water storage containers}

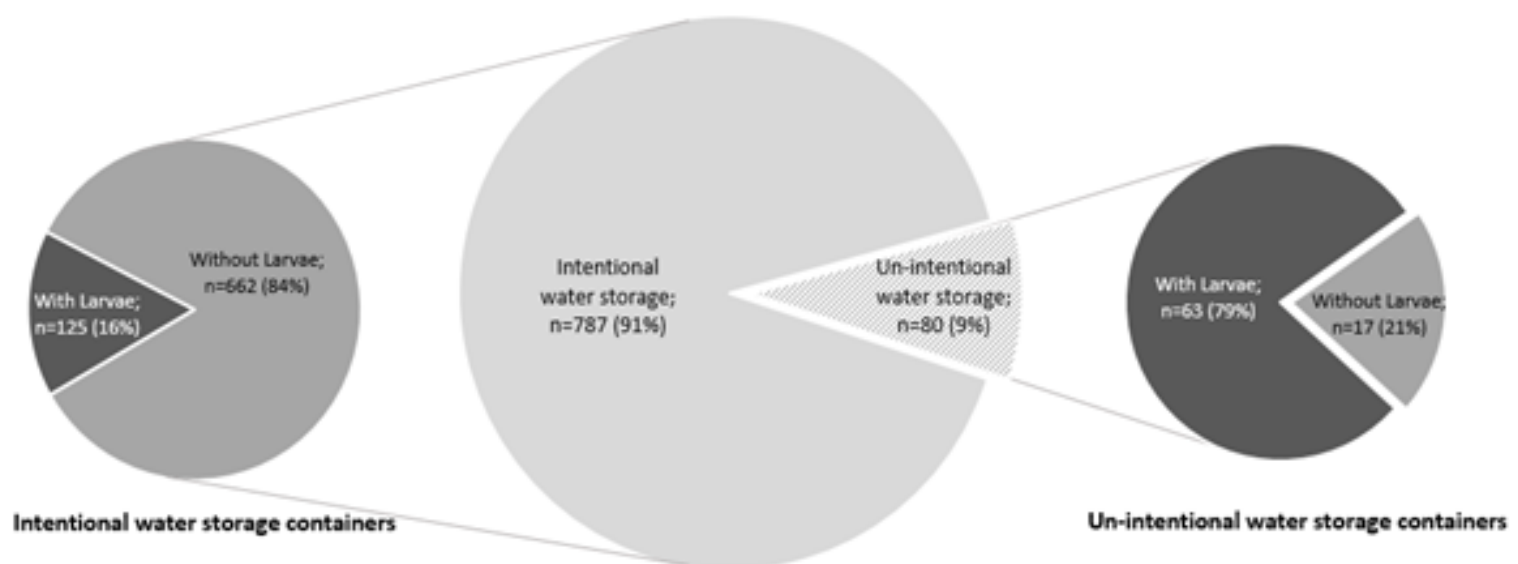

Legend:

Intentional water storage

Un-intentional water storage

With larvae

Without larvae

\section{Figure 3}

Proportion of intentional and unintentional storage containers with Aedes larvae mosquitoes.

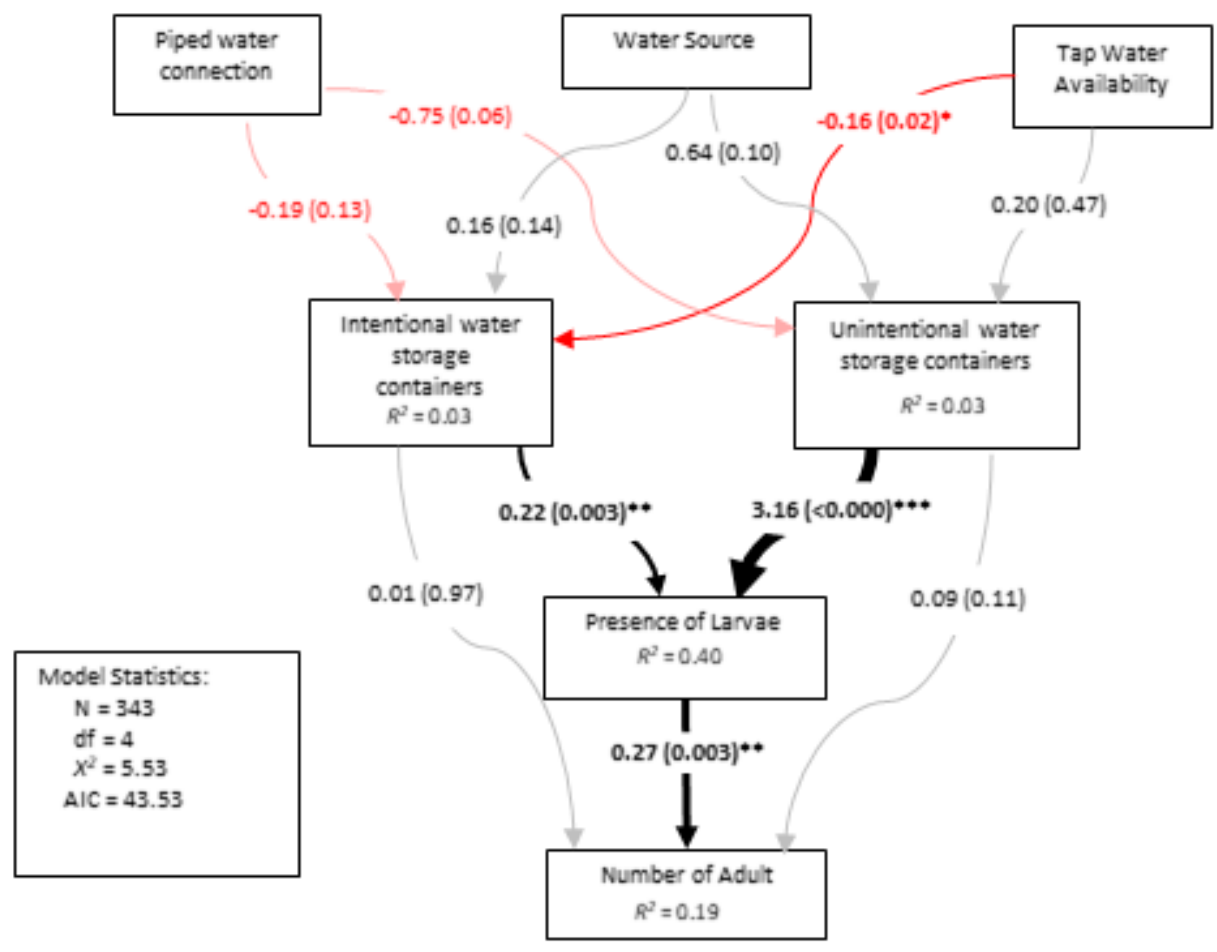

Figure 4 
Piecewise SEM model of the interaction among water supply conditions, water storage containers, and vector prevalence and abundance. Boxes represent measured variables with R2 component models; Arrows represent unidirectional relationship among variables; black arrows denote positive relationships and red arrows negative ones; arrows for non-significant paths $(P>.05)$ are semi-transparent; the thickness of the significant paths has been scaled based on the magnitude of the standardized regression coefficient (indicated in the mid-line with $p$-values in parentheses); $\mathrm{df}=$ degrees of freedom; $\mathrm{X} 2$ $=$ chi-square value; $\mathrm{AIC}=$ akaike information criterion; $\mathrm{P}<0.001 * \star * ; P<0.01 * * ; \mathrm{P}<0.05^{\star}$

\section{Supplementary Files}

This is a list of supplementary files associated with this preprint. Click to download.

- MSWMAF1.docx

- MSWMAF2.docx

- MSWMAF3.docx

- MSWMAF4.docx

- MSWMGraphicalAbstract.pptx 